\title{
PENILAIAN PUSKESMAS DAN RUMAH SAKIT TENTANG EFEKTIVITAS SISTEM RUJUKAN MATERNAL DI KOTA SURABAYA
}

\author{
ASSESSMENT OF HEALTH CENTERS AND HOSPITALS ABOUT THE EFFECTIVENESS OF MATERNAL \\ REFERRAL SYSTEM IN SURABAYA DISTRICT
}

Stevie Yonara, Ratna Dwi Wulandari

Fakultas Kesehatan Masyarakat, Universitas Airlangga, Surabaya

E-mail: stevie.yonara@yahoo.co.id

\begin{abstract}
More than $80.0 \%$ maternal deaths occured in hospital in Surabaya between 2012-2014. Most of them who died in hospital were referral patients from midwife, private clinics, and public health centers. This study assessed the effectiveness of maternal referral system based on perspective of public health centers and hospitals in Surabaya. This was a descriptive cross sectional study. Samples were 43 public health centers in Surabaya and two main referral destination hospitals. Data was collected by interviewing one representative midwife in each public health center and hospital. This study showed that a total of $81.4 \%$ health centers assess that maternal referral system in Surabaya District was quite effective. While, one of the hospital assessed quite effective, and the other assessed less effective. The reason was because public health centers difficulty to contacting hospitals about referral, hospitals often rejected referral case, pregnant women often do self-referral to hospital, and incompatibility referral reason by most of public health centers. So it was necessary to repair maternal referral system at Surabaya based on identification of each variables in effectiveness of maternal referral system.
\end{abstract}

Keywords: effectiveness, hospitals, maternal refferal system, public health center

\section{PENDAHULUAN}

Kesehatan merupakan salah satu hal yang menjadi perhatian pemerintah dalam rangka meningkatkan pembangunan negara. Oleh karena itu, pembangunan di bidang kesehatan sangatlah penting. Perhatian terhadap kesehatan tidak hanya menjadi perhatian negara Indonesia saja, melainkan juga menjadi perhatian dunia internasional.

Pada bulan September tahun 2000, 189 negara anggota Perserikatan Bangsa-Bangsa (PBB) mengikuti Konferensi Tingkat Tinggi Milenium di New York. Dalam konferensi ini, semua negara yang hadir mendeklarasikan Millenium Development Goals (MDGs) yang merupakan paradigma pembangunan global. Berdasarkan tujuan yang tertera dalam MDGs, kesehatan ibu merupakan salah satu hal yang menjadi perhatian, yaitu pada tujuan meningkatkan kesehatan ibu. Dalam tujuan tersebut, target yang ingin dicapai adalah menurunkan AKI (Angka Kematian lbu) sebesar tiga perempatnya antara tahun 1990 dan 2015.

Pada tahun 2012, kota Surabaya berada pada peringkat ke-6 se-Jawa Timur dengan AKI sebesar 144,64 per 100.000 kelahiran hidup. Angka tersebut masih jauh dari target MDGs yaitu sebesar 102 per 100.000 kelahiran hidup. Selain data AKI, juga didapat data proporsi tempat kematian ibu di Kota Surabaya, di mana diketahui bahwa kematian ibu paling banyak terjadi di rumah sakit yaitu sebesar $88,3 \%$ pada tahun $2012,85,7 \%$ pada tahun 2013 , dan $94,9 \%$ pada tahun 2014. Berdasarkan data tersebut, bisa dilihat bahwa meskipun jumlah kematian ibu di rumah sakit menurun pada tahun 2013, terjadi kenaikan yang tajam di tahun 2014 hingga mencapai 94,9\%. Rumah sakit merupakan fasilitas kesehatan tingkat lanjut, sehingga dapat disimpulkan bahwa sebagian besar ibu yang 
meninggal di rumah sakit tersebut merupakan pasien rujukan dari bidan, klinik swasta, maupun Puskesmas. Oleh karena itu, masalah yang diangkat dalam dalam penelitian ini adalah terjadinya peningkatan yang tajam pada jumlah kematian ibu di rumah sakit di Kota Surabaya pada tahun 2014, dari 85,7\% pada tahun 2013 menjadi 94,9\% pada tahun 2014.

Penelitian ini mengidentifikasi efektivitas sistem rujukan maternal di Puskesmas dan rumah sakit di Kota Surabaya berdasarkan penilaian bidan Puskesmas dan rumah sakit. Hasil dari penelitian ini diharapkan dapat menjadi bahan acuan untuk meningkatkan efektivitas sistem rujukan maternal di Kota Surabaya.

\section{PUSTAKA}

Berdasarkan KMK No.604 tahun 2008 tentang Pedoman Pelayanan Maternal Perinatal pada Rumah Sakit Umum Kelas B dan C, disebutkan bahwa fasilitas kesehatan maternal perinatal dibagi dalam tiga tingkat, yaitu primer (Puskesmas, Bidan), sekunder (Rumah Sakit), dan tersier (Rumah Sakit rujukan dengan fasilitas perawatan intensif dan superspesialis). Karena perbedaan kemampuan dan fasilitas yang dimiliki masing-masing pemberi pelayanan kesehatan maternal, maka dilakukan rujukan maternal ke fasilitas kesehatan maternal yang lebih mampu menangani sesuai dengan hirarki rujukan yang telah disebutkan.

Dalam melaksanakan rujukan, ada hal-hal yang perlu diperhatikan, yaitu hal-hal yang menyangkut tingkat kemampuan tempat rujukan, sarana yang dibutuhkan, waktu dan jarak tempuh, serta tingkat kegawatan penderita. Seperti yang telah disebutkan di atas, waktu adalah salah satu hal penting yang harus diperhatikan dalam melaksanakan rujukan.

Langkah-langkah yang harus dilakukan dalam melaksanakan rujukan maternal sesuai dengan Pedoman Rujukan Medik Puskesmas tahun 1990 adalah menentukan kegawatdaruratan penderita, menentukan tempat tujuan rujukan, memberikan informasi kepada penderita dan keluarganya, mengirimkan informasi pada tempat rujukan yang dituju, mempersiapkan penderita dan mengirimkan penderita menuju tempat rujukan.

Untuk mengetahui efektivitas dari sistem rujukan maternal, indikator yang dapat digunakan adalah appropriate dan timely (Rowland, McLeod, \& Froese-Burns, 2012). Berdasarkan hasil penelitian Yonara (2015), diketahui pula bahwa indikator appropriate dan timely dapat digunakan sebagai indikator pengukuran efektivitas sistem rujukan maternal. Appropriate (Kesesuaian) adalah tentang kesesuaian dari rujukan yang dilakukan. Ada 2 hal yang perlu diperhatikan, yaitu by-passing dan non compliance with refferal advice (Murray \& Pearson, 2006). By-passing adalah rujukan yang dilakukan tidak sesuai dengan tahapan rujukan yang telah ditentukan, yaitu melewati fasilitas kesehatan yang lebih rendah. Dari mana asal rujukan penting untuk diperhatikan, apakah sudah sesuai dengan alur rujukan atau belum. Selain itu, hal ini juga bisa disebabkan karena adanya self-refferal (rujukan yang dilakukan oleh ibu hamil sendiri, di mana ibu 
hamil tersebut langsung datang pada fasilitas kesehatan yang berada di tingkat yang lebih tinggi, tanpa ke fasilitas kesehatan tingkat rendah terlebih dahulu).

Non compliance with refferal advice adalah rujukan yang seharusnya tidak perlu dilakukan. Untuk mengukur indikator ini harus dilakukan pemeriksaan pada pendaftaran pasien di fasilitas. Dari setiap rujukan yang dilakukan, pasti ada alasan mengapa ibu hamil tersebut dirujuk. Alasan rujukan tersebut harus sesuai dengan alasan rujukan berjenjang, tidak boleh ada rujukan dengan alasan yang tidak jelas.

Indikator kedua yang digunakan adalah timely (Tepat Waktu). Timely (tepat waktu) ini berkaitan dengan beberapa hal, yaitu response time for communication dan timely treatment of complication. Response time for communication ini meliputi seberapa lama waktu yang diperlukan untuk berkomunikasi dengan fasilitas tempat ibu hamil akan dirujuk. Semakin cepat tentunya menunjukkan bahwa sistem rujukan efektif. Komunikasi ini juga meliputi bagaimana kondisi ibu hamil yang akan dirujuk. Timely treatment of complication ini merupakan kecepatan dalam penanganan kasus komplikasi di fasilitas kesehatan rujukan. Semakin cepat penanganan, maka semakin efektif pula sistem rujukan.

\section{METODE}

Penelitian ini merupakan penelitian deskriptif dengan desain cross-sectional. Populasi penelitian adalah Puskesmas dan rumah sakit yang ada di kota Surabaya. Berdasarkan pelayanan maternal yang diberikan, Puskesmas dibedakan menjadi Puskesmas PONED dan Non PONED. Ada 8 Puskesmas PONED di Kota Surabaya. Kedelapan Puskesmas tersebut yang menjadi sampel penelitian. Selain itu, ada 54 Puskesmas Non PONED di kota Surabaya. Dari 54 Puskesmas tersebut dilakukan sampling dengan menggunakan metode simple random sampling, sehingga didapat 35 Puskesmas Non PONED yang menjadi sampel penelitian.

Rumah sakit yang menjadi sampel penelitian adalah rumah sakit yang paling sering menjadi tujuan rujukan maternal oleh Puskesmas. Mayoritas Puskesmas yang diwawancarai menyebutkan bahwa rumah sakit yang paling sering menjadi tujukan rujukan oleh Puskesmas adalah RSUD Dr. Mohamad Soewandhie sebesar 58,1\%, RSUD Bhakti Dharma Husada sebesar 27,9\%, RS Haji sebesar 6,9\%, RSI sebesar 4,8\%, serta RS Pura Raharja sebesar 2,3\%. Oleh karena itu, RSUD Dr. Mohamad Soewandhie dan RSUD Bhakti Dharma Husada diambil sebagai sampel penelitian. Puskesmas dan rumah sakit yang menjadi sampel penelitian dilihat sebagai organisasi, sehingga nantinya akan dilakukan pengumpulan data pada satu bidan koordinator atau bidan lain yang paham tentang rujukan maternal sebagai perwakilan dari setiap Puskesmas dan rumah sakit.

Penelitian ini dilaksanakan pada awal bulan Januari sampai akhir bulan Juli tahun 2015 . Pengumpulan data dilakukan dengan cara wawancara pada satu bidan pada setiap Puskesmas 
dan satu bidan pada setiap rumah sakit yang menjadi sampel penelitian. Data yang didapat dari wawancara kemudian dikelompokkan berdasarkan variabel yang digunakan. Ada 2 variabel yang digunakan untuk mengidentifikasi efektivitas sistem rujukan maternal, yaitu appropriate dan timely. Appropriate merupakan variabel pada rumah sakit sedangkan timely merupakan variabel pada Puskesmas. Setelah itu dilakukan pengkategorian efektivitas sistem rujukan maternal berdasarkan jawaban pada variabel.

\section{HASIL \& PEMBAHASAN}

\section{Penilaian Efektivitas Sistem Rujukan Maternal pada Puskesmas}

Identifikasi efektivitas sistem rujukan maternal pada Puskesmas dilakukan dengan identifikasi variabel Timely (ketepatan waktu). Indikator yang digunakan pada variabel timely adalah response time dan timely treatment of complication. Response time adalah kecepatan respon komunikasi rumah sakit tempat merujuk saat Puskesmas menghubungi untuk melakukan rujukan berdasarkan persepsi bidan Puskesmas. Sedangkan timely treatment of complication adalah kecepatan penanganan kasus rujukan yang dilakukan oleh rumah sakit tempat merujuk berdasarkan persepsi bidan Puskesmas.

Indikator pertama yang digunakan adalah response time. Berdasarkan Tabel 1 diketahui bahwa masih ada bidan Puskesmas yang menjawab sangat lambat, yaitu sebesar 2,3\%. Hal ini dikarenakan beberapa kali terjadi saat bidan Puskesmas menelepon rumah sakit penerima rujukan, harus menunggu hingga paling lama 20 menit untuk mendapat konfirmasi kesediaan menerima rujukan. Selain itu, bidan tersebut juga menyatakan bahwa ada rumah sakit yang susah dihubungi, terutama pada malam hari.

Tabel 1 Distribusi Frekuensi Penilaian Bidan Puskesmas Terhadap Kecepatan Respon Komunikasi (Response Time) Berdasarkan Klasifikasi Puskesmas dan Rumah Sakit Penerima Rujukan Maternal Terbanyak di Kota Surabaya

\begin{tabular}{|c|c|c|c|c|c|c|c|c|c|c|}
\hline \multirow{2}{*}{$\begin{array}{c}\text { Fasilitas } \\
\text { Kesehatan } \\
\text { Maternal }\end{array}$} & \multicolumn{2}{|c|}{ Sangat Cepat } & \multicolumn{2}{|c|}{ Cepat } & \multicolumn{2}{|c|}{ Lambat } & \multicolumn{2}{|c|}{$\begin{array}{l}\text { Sangat } \\
\text { Lambat }\end{array}$} & \multicolumn{2}{|c|}{ Total } \\
\hline & $\mathbf{n}$ & $\%$ & $\mathbf{n}$ & $\%$ & $\mathbf{n}$ & $\%$ & $\mathbf{n}$ & $\%$ & $\mathbf{n}$ & $\%$ \\
\hline \multicolumn{11}{|l|}{ Puskesmas } \\
\hline PONED & 0 & 0,0 & 5 & 11,7 & 3 & 6,9 & 0 & 0,0 & 8 & 18,6 \\
\hline Non PONED & 2 & 4,7 & 26 & 60,5 & 6 & 13,9 & 1 & 2,3 & 35 & 81,4 \\
\hline Total & 2 & 4,7 & 31 & 72,2 & 9 & 20,8 & 1 & 2,3 & 43 & 100,0 \\
\hline \multicolumn{11}{|l|}{ Rumah Sakit } \\
\hline RSUD & & & & & & & & & & \\
\hline Mohamad & 2 & 8,0 & 18 & 72,0 & 4 & 16,0 & 1 & 4,0 & 25 & 100,0 \\
\hline Soewandhie & & & & & & & & & & \\
\hline $\begin{array}{l}\text { RSUD Bhakti } \\
\text { Dharma Husada }\end{array}$ & 0 & 0,0 & 8 & 66,7 & 4 & 33,3 & 0 & 0,0 & 12 & 100,0 \\
\hline RS Haji & 2 & 66,7 & 1 & 33,3 & 0 & 0,0 & 0 & 0,0 & 3 & 100,0 \\
\hline $\mathrm{RSI}$ & 0 & 0,0 & 2 & 100,0 & 0 & 0,0 & 0 & 0,0 & 2 & 100,0 \\
\hline RS Pura Raharja & 0 & 0,0 & 1 & 100,0 & 0 & 0,0 & 0 & 0,0 & 1 & 100,0 \\
\hline
\end{tabular}


Selain itu, masih ada Puskesmas yang mengatakan lambat, yaitu sebesar $16,0 \%$ pada RSUD Dr. Mohamad Soewandhie, serta 33,3\% pada RSUD Bhakti Dharma Husada. Bahkan masih ada 2,3\% bidan Puskesmas yang mengatakan sangat lambat, yaitu pada RSUD Dr. Mohamad Soewandhie. Hal ini dikarenakan beberapa kali terjadi saat bidan Puskesmas menelepon rumah sakit penerima rujukan, harus menunggu hingga paling lama 20 menit untuk mendapat konfirmasi kesediaan menerima rujukan.

Salah satu syarat dari sistem rujukan yang efektif adalah sistem komunikasi yang baik (Murray, Davies, Phiri, \& Ahmed, 2001). Komunikasi yang dimaksud adalah komunikasi dalam rangka pelayanan kasus rujukan maternal, antara pelayanan kesehatan maternal primer, sekunder dan tersier. Terutama untuk kasus rujukan maternal, kecepatan respon komunikasi dari rumah sakit penerima rujukan merupakan hal yang krusial, dikarenakan kondisi ibu yang gawat membutuhkan penanganan yang cepat.

Salah satu faktor yang mempengaruhi tingginya angka kematian ibu adalah proses rujukan yang terlambat (Irasanty, Hakimi, \& Hasanbasri, 2008). Masih adanya Puskesmas perujuk yang menyatakan bahwa respon dari rumah sakit lambat, maka perlu ditinjau kembali bagaimana sistem komunikasi dalam pelaksanaan rujukan. Padahal kecepatan respon dalam keadaan darurat sangatlah penting dan krusial (Kapucu, 2006). Sebaiknya rumah sakit penerima rujukan bisa memperbaiki jalur komunikasinya agar mudah dihubungi oleh puskesmas perujuk. Atau bisa juga dengan membuat line (nomor telepon) komunikasi khusus untuk rujukan maternal, sehingga arus komunikasi yang masuk tidak sibuk.

Dalam kaitannya dengan komunikasi, follow up sangat penting untuk dilakukan dalam pelaksanaan sistem rujukan (Antonelli, McAllister \& Pop, 2009). Sebagian besar bidan Puskesmas mengatakan bahwa setelah pasien rujukan diterima oleh rumah sakit penerima rujukan, maka pasien tersebut sepenuhnya merupakan tanggung jawab dari rumah sakit yang menerima rujukan. Karena bukan tanggung jawabnya lagi, maka bidan pun merasa tidak perlu melakukan follow up tentang keadaan pasien selama penanganan.

Pemikiran tersebut tidak sesuai dengan teori koordinasi antar organisasi atau interorganizational coordination (IOC). Karena dalam teori IOC, komunikasi ini berperan penting untuk bisa terciptanya IOC yang efektif (Antonelli, McAllister \& Pop, 2009). Tanpa IOC yang baik, tentu saja sistem rujukan maternal pun tidak dapat berjalan dengan baik. Jika komunikasi saja buruk, pasti IOC pun buruk. Karena efektivitas IOC ini berpengaruh terhadap efektivitas sistem rujukan maternal, maka tentu saja sistem rujukan maternal juga menjadi buruk. Sebaiknya dibuat kesepakatan frekuensi waktu untuk melakukan follow up keadaan ibu yang dirujuk, misalnya sehari sekali selama 3 hari berturutturut.

Selain itu, bidan rumah sakit pun menyatakan bahwa kedua bidan rumah sakit tidak pernah melakukan feedback pada bidan Puskesmas 
Tabel 2 Distribusi Frekuensi Penilaian Bidan Puskesmas Terhadap Kecepatan Penanganan Kasus Rujukan Berdasarkan Klasifikasi Puskesmas dan Rumah Sakit Penerima Rujukan Maternal Terbanyak di Kota Surabaya

\begin{tabular}{|c|c|c|c|c|c|c|c|c|c|c|}
\hline \multirow{2}{*}{$\begin{array}{c}\text { Fasilitas } \\
\text { Kesehatan } \\
\text { Maternal }\end{array}$} & \multicolumn{2}{|c|}{ Sangat Cepat } & \multicolumn{2}{|c|}{ Cepat } & \multicolumn{2}{|c|}{ Lambat } & \multicolumn{2}{|c|}{ Sangat Lambat } & \multicolumn{2}{|c|}{ Total } \\
\hline & $\mathbf{n}$ & $\%$ & $\mathbf{n}$ & $\%$ & $\mathbf{n}$ & $\%$ & $\mathbf{n}$ & $\%$ & $\mathbf{n}$ & $\%$ \\
\hline \multicolumn{11}{|l|}{ Puskesmas } \\
\hline PONED & 0 & 0,0 & 8 & 18,6 & 0 & 0,0 & 0 & 0,0 & 8 & 18,6 \\
\hline Non PONED & 6 & 14,0 & 29 & 67,4 & 0 & 0,0 & 0 & 0,0 & 35 & 81,4 \\
\hline Total & 6 & 14,0 & 37 & 86,0 & 0 & 0,0 & 0 & 0,0 & 43 & 100,0 \\
\hline \multicolumn{11}{|l|}{ Rumah Sakit } \\
\hline RSUD Dr. & & & & & & & & & & \\
\hline $\begin{array}{l}\text { Mohamad } \\
\text { Soewandhie }\end{array}$ & 4 & 16,0 & 21 & 84,0 & 0 & 0,0 & 0 & 0,0 & 25 & 100,0 \\
\hline $\begin{array}{l}\text { RSUD Bhakti } \\
\text { Dharma Husada }\end{array}$ & 1 & 8,3 & 11 & 91,7 & 0 & 0,0 & 0 & 0,0 & 12 & 100,0 \\
\hline RS Haji & 1 & 33,3 & 2 & 66,7 & 0 & 0,0 & 0 & 0,0 & 3 & 100,0 \\
\hline RSI & 0 & 0,0 & 2 & 100,0 & 0 & 0,0 & 0 & 0,0 & 2 & 100,0 \\
\hline $\begin{array}{l}\text { RS Pura } \\
\text { Raharja }\end{array}$ & 0 & 0,0 & 1 & 100,0 & 0 & 0,0 & 0 & 0,0 & 1 & 100,0 \\
\hline
\end{tabular}

perujuk. Padahal berdasarkan Permenkes No.001 tahun 2012 tentang Jaminan Kesehatan, disebutkan bahwa penerima rujukan wajib memberikan informasi kepada perujuk mengenai perkembangan keadaan pasien setelah selesai memberikan pelayanan. Feedback penting untuk dilakukan oleh rumah sakit penerima rujukan supaya perujuk mempunyai informasi yang cukup untuk nantinya melanjutkan perawatan dari pasien setelah perawatan di pelayanan kesehatan penerima rujukan selesai (Antonelli, McAllister \& Pop, 2009). Follow up atau feedback dari rumah sakit penerima rujukan ini penting untuk dilakukan karena berhubungan dengan kepuasan perujuk dalam pelaksanaan koordinasi rujukan (Forrest, Glade, Baker, Bocian, Schrader, \& Starfield, 2000).

Oleh karena itu, perlu dibuat ketentuan yang jelas dan tertulis tentang komunikasi yang seharusnya dilakukan antara perujuk dan penerima rujukan di Kota Surabaya. Minimal harus ada pedoman yang jelas agar dapat menjadi bahan evaluasi pelayanan kesehatan maternal (Antonelli, McAllister \& Pop, 2009).

$$
\text { Indikator selanjutnya adalah timely }
$$
treatment of complication. Berdasarkan Tabel 2, diketahui bahwa persentase jawaban terbanyak pada Puskesmas untuk indikator timely treatment of complication adalah cepat yaitu sebesar $86,0 \%$. Hal ini berarti kecepatan penanganan pada rumah sakit penerima rujukan sudah baik dan perlu dipertahankan. Diketahui pula bahwa tidak ada rumah sakit penerima rujukan yang dinilai lambat maupun sangat lambat dalam menangani kasus rujukan.

Dalam kaitannya dengan komunikasi rujukan, ada pula bidan Puskesmas yang bercerita bahwa pernah terjadi saat bidan Puskesmas merujuk ibu hamil prematur tetapi semua penerima rujukan di Surabaya yang dihubungi menolak untuk menerima dengan alasan tidak mampu menangani. Padahal menurut bidan Puskesmas seharusnya penerima rujukan mampu menangani kasus tersebut dilihat dari tenaga dan fasilitas yang tersedia di sana. Pada 
akhirnya, bidan Puskesmas pun menghubungi penerima rujukan di daerah Sidoarjo, dan beruntung penerima rujukan tersebut mau menerima. Menurut bidan Puskesmas tersebut, jika dibandingkan berdasarkan tenaga dan fasilitas yang tersedia seharusnya penerima rujukan di Surabaya lebih mampu bahkan sangat mampu menangani kasus rujukan tersebut. Tentunya hal ini membuat penanganan ibu menjadi lama, sehingga bisa terjadi penanganan yang tidak tepat waktu (timely).

Permasalahan di atas dapat disebabkan karena ketidakjelasan dalam prosedur penerimaan dan penolakan rujukan, yaitu kasus rujukan apa saja yang dapat diterima oleh rumah sakit penerima rujukan. Prosedur dan acuan yang jelas tentang identifikasi komplikasi yang dapat diterima oleh rumah sakit penerima rujukan harus ada agar tercipta sistem rujukan yang efektif (Murray, Davies, Phiri, \& Ahmed, 2001).

Keterlambatan dalam penanganan kasus rujukan sangat berpengaruh terhadap kejadian kematian ibu (Simbolon, Chalidyanto, \& Ernawati, 2013). Keterlambatan penanganan ibu dapat menyebabkan timbulnya masalah-masalah lain yang lebih rumit. Dalam kaitannya dengan variabel timely, UGD di rumah sakit tentunya memegang peranan penting dalam pelaksanaan sistem rujukan. Harus tersedia pelayanan yang cepat dan tepat di UGD (Simbolon, Chalidyanto, \& Ernawati, 2013).

Masih berkaitan dengan UGD, berdasarkan penuturan bidan Puskesmas ada salah satu rumah sakit penerima rujukan yang ruang operasinya belum beroperasi 24 jam. Padahal sebagai salah satu ijin rumah sakit, rumah sakit di Indonesia berkewajiban untuk menyelenggarakan pelayanan gawat darurat 24 jam sehari (Simbolon, Chalidyanto, \& Ernawati, 2013). Begitu pula dengan dokter spesialis obgyn di rumah sakit tersebut yang hanya ada pada jam dinas saja. Hal ini perlu diperhatikan oleh manajemen internal rumah sakit, terutama ketersediaan fasilitas dan sumber daya yang memadai untuk menunjang pelayanan kesehatan.

Dalam kaitannya dengan timely treatment of complication, diketahui pula bahwa terkadang bidan Puskesmas itu sendiri yang menyebabkan penanganan kasus rujukan menjadi tidak tepat waktu. Berdasarkan pernyataan bidan rumah sakit, hal ini dikarenakan data kondisi ibu yang dirujuk oleh Puskesmas dinilai tidak jelas. Ketidakjelasan data kondisi ibu ini terjadi karena seringkali terjadi pasien rujukan tidak diantar oleh bidan perujuk, serta sering pula terjadi bahwa apa yang tertulis pada data kondisi ibu tidak sesuai dengan realita kondisi ibu. Ada beberapa perujuk yang sengaja membaikbaikkan kondisi ibu agar diterima oleh rumah sakit. Ternyata setelah diterima oleh rumah sakit, ibu yang dirujuk tersebut sangat gawat dan rumah sakit tidak mampu menangani. Pada akhirnya ibu yang dirujuk tadi harus diestafet ke penerima rujukan lain yang mampu menangani. Hal ini tentu saja membuangbuang waktu, padahal untuk kasus darurat, waktu merupakan hal yang krusial.

Setelah mengidentifikasi indikator dari variabel timely, maka dilakukan identifikasi variabel timely. Tetapi, karena hanya satu indikator yang digunakan pada Puskesmas, maka identifikasi 
Tabel 3 Distribusi Kategori Efektivitas Sistem Rujukan Maternal di Kota Surabaya

\begin{tabular}{lcccccc}
\hline \multirow{2}{*}{ Kategori } & \multicolumn{2}{c}{ Puskes-mas PONED } & \multicolumn{2}{c}{$\begin{array}{c}\text { Puskes-mas Non } \\
\text { PONED }\end{array}$} & \multicolumn{2}{c}{ Total } \\
\cline { 2 - 6 } & $\mathbf{n}$ & $\%$ & $\mathbf{n}$ & \% & $\mathbf{n}$ & $\%$ \\
\hline Efektif & 0 & 0,0 & 7 & 16,3 & $\mathbf{7}$ & $\mathbf{1 6 , 3}$ \\
\hline Cukup Efektif & 8 & 18,6 & 27 & 62,8 & $\mathbf{3 5}$ & $\mathbf{8 1 , 4}$ \\
\hline Kurang Efektif & 0 & 0,0 & 1 & 2,3 & $\mathbf{1}$ & $\mathbf{2 , 3}$ \\
\hline Total & $\mathbf{8}$ & $\mathbf{1 8 , 6}$ & $\mathbf{3 5}$ & $\mathbf{8 1 , 4}$ & $\mathbf{4 3}$ & $\mathbf{1 0 0 , 0}$ \\
\hline
\end{tabular}

Tabel 4 Penilaian Bidan Rumah Sakit Terhadap Kesesuaian Tahapan dan Alasan Rujukan yang Dilakukan (Appropriate) oleh Puskesmas Perujuk di Kota Surabaya

\begin{tabular}{lcc}
\hline \multicolumn{1}{c}{ Indikator } & $\begin{array}{c}\text { RSUD Dr. Mohamad } \\
\text { Soewandhie }\end{array}$ & RSUD Bhakti Dharma Husada \\
\hline Kesesuaian Tahapan Rujukan & Tidak Sesuai & Tidak Sesuai \\
\hline Kesesuaian Alasan Rujukan & Sesuai & Tidak Sesuai \\
\hline
\end{tabular}

variabel timely ini digunakan untuk mengidentifikasi efektivitas sistem rujukan maternal dengan cara menjumlahkan skor tiap indikator dan mengkategorikan dalam kategori kurang efektif, cukup efektif, dan efektif.

Dari Tabel 3 di atas, diketahui bahwa berdasarkan persentase terbanyak, Puskesmas PONED maupun Puskesmas Non PONED berada pada kategori cukup efektif, dengan persentase sebesar $81,4 \%$. Perlu dilakukan perbaikan pada pelaksanaan sistem rujukan maternal.

\section{Efektivitas Sistem Rujukan Maternal pada Rumah} Sakit

Untuk mengukur efektivitas sistem rujukan maternal digunakan variabel pengukuran appropriate. Appropriate merupakan kesesuaian dalam pelaksanaan rujukan maternal. Untuk mengukur variabel appropriate digunakan dua indikator, yaitu kesesuaian tahapan rujukan dan kesesuaian alasan rujukan berdasarkan penilaian bidan rumah sakit terhadap kasus rujukan maternal yang diterima secara umum. Berikut ini penilaian bidan rumah sakit terhadap kesesuaian tahapan dan alasan rujukan yang dilakukan (appropriate) oleh Puskesmas perujuk.

Berdasarkan Tabel 4, diketahui bahwa untuk indikator kesesuaian tahapan rujukan kedua rumah sakit menyatakan tidak sesuai. Ketidaksesuaian tahapan rujukan ini disebabkan karena masih ada beberapa ibu hamil yang melakukan rujukan sendiri tanpa memperhatikan tahapan rujukan. Ibu hamil yang melakukan rujukan sendiri ini disebut self-referral. Adanya self-referral ini menunjukkan bahwa terjadi by-passing, yaitu rujukan yang melompati tahap rujukan yang lebih rendah (tidak sesuai dengan tahapan rujukan). Ketidaksesuaian tahapan rujukan ini dapat merugikan rumah sakit penerima rujukan dikarenakan rumah sakit penerima rujukan dapat terbebani dengan jumlah rujukan yang ada (Murray, Davies, Phiri, \& Ahmed, 2001). Padahal sumber daya yang ada di rumah sakit penerima rujukan juga terbatas. Jika hal ini sering terjadi dan terjadi terus- 
menerus, maka sistem rujukan yang ada menjadi tidak efektif.

Perlu dibuat sebuah prosedur/mekanisme untuk memastikan ibu hamil tidak melakukan bypassing. Prosedur/mekanisme yang dibuat dapat berupa pemberian informasi pada ibu hamil, dan sistem pengecualian (Murray, Davies, Phiri, \& Ahmed, 2001). Pemberian informasi pada ibu hamil berupa informasi tentang tahapan rujukan yang seharusnya, bahwa rujukan harus dilakukan dari fasilitas kesehatan tingkat pertama. Selain pemberian informasi, sistem pengecualian juga harus dibuat. Sistem pengecualian ini meliputi kondisi apa saja yang menjadi syarat pengecualian dalam pelaksanaan rujukan yang berjenjang. Adanya syarat yang jelas, dapat mengurangi terjadinya bypassing dalam pelaksanaan rujukan maternal.

Selain itu, diketahui pula bahwa bidan RSUD Bhakti Dharma Husada memberi jawaban tidak sesuai untuk indikator kesesuaian alasan rujukan. Seperti yang sudah dijelaskan sebelumnya, ketidaksesuaian ini terjadi karena seringkali perujuk salah diagnosa dan analisa, sehingga ibu yang seharusnya tidak dirujuk tetapi malah dirujuk, dan sebaliknya. Selain itu juga seringkali terjadi perbedaan antara realita kondisi ibu dengan data kondisi ibu. Ketelitian bidan Puskesmas perujuk harus lebih ditingkatkan lagi, agar tidak terjadi lagi alasan rujukan yang tidak sesuai.

Setelah mengidentifikasi indikator dari variabel appropriate, maka dilakukan identifikasi variabel appropriate. Tetapi, karena hanya satu indikator yang digunakan pada rumah sakit, maka identifikasi variabel appropriate ini digunakan untuk mengidentifikasi efektivitas sistem rujukan maternal dengan cara menjumlahkan skor tiap indikator dan mengkategorikan dalam kategori kurang efektif, cukup efektif, dan efektif. Berdasarkan penjumlahan skor yang dilakukan, diketahui bahwa RSUD Dr. Mohamad Soewandhie berada kategori cukup efektif dan RSUD Bhakti Dharma Husada pada kategori kurang efektif.

\section{SIMPULAN}

Sebagian besar Puskesmas menilai bahwa sistem rujukan maternal di Kota Surabaya adalah cukup efektif. Hal ini dikarenakan ada Puskesmas yang sulit dalam menghubungi rumah sakit penerima rujukan untuk melakukan rujukan. Selain itu, masih sering pula terjadi penolakan rujukan dengan alasan rumah sakit tidak mampu menangani, padahal jika dilihat dari fasilitas dan sumber daya yang tersedia, rumah sakit tersebut mampu menangani kasus rujukan tersebut. Begitu juga dengan rumah sakit, RSUD Dr. Mohamad Soewandhie menilai bahwa sistem rujukan maternal di Kota Surabaya adalah cukup efektif, serta RSUD Bhakti Dharma Husada menilai kurang efektif. Hal ini dikarenakan masih sering terjadi self-referral oleh ibu hamil, serta ketidaksesuaian alasan rujukan.

Dalam rangka peningkatan efektivitas sistem rujukan maternal di kota Surabaya sebaiknya rumah sakit penerima rujukan memperbaiki jalur komunikasinya agar mudah dihubungi oleh Puskesmas perujuk. Rumah sakit dapat membuat line (nomor telepon) komunikasi khusus untuk 
rujukan maternal, sehingga arus komunikasi yang masuk tidak sibuk.

Sebaiknya dibuat sebuah kesepakatan di antara Puskesmas perujuk dan rumah sakit penerima rujukan tentang kasus rujukan dengan kondisi yang seperti apa yang dapat diterima oleh sebuah fasilitas kesehatan penerima rujukan. Kesepakatan tersebut harus dituliskan berdasarkan tenaga dan fasilitas yang ada di fasilitas kesehatan penerima rujukan tersebut.

Sebaiknya dibuat pula ketentuan yang jelas mengenai penolakan kasus rujukan oleh rumah sakit, dalam arti dengan keadaan seperti apa saja sebuah fasilitas kesehatan penerima rujukan (rumah sakit) dapat menolak kasus rujukan. Selain itu, sebaiknya dilakukan evaluasi aturan dan pelaksanaan rujukan maternal oleh Dinas Kesehatan. Terutama dengan adanya BPJS, perlu dilakukan penataan ulang jejaring rujukan dan sosialisasi pada Puskesmas tentang daftar rumah sakit penerima rujukan yang bekerja sama dengan BPJS yang berada paling dekat dengan Puskesmas.

\section{DAFTAR PUSTAKA}

Antonelli, R. C., McAllister, J. W., \& Popp, J. (2009). Making Care Coordination A Critical Component of The Pediatric Health System: A Multidisciplinary Framework. US: The Commonwealth Fund Press.

Forrest, C. B., Glade, G. B., Baker, A. E., Bocian, A., Schrader, S. V., \& Starfield, B. (2000). Coordination of Specialty Referrals and Physician Satisfaction With Referral Care. JAMA Pediatrics, 499-506.

Irasanty, G. D., Hakimi, M., \& Hasanbasri, M. (2008). Pencegahan Keterlambatan Rujukan Maternal di Kabupaten Majene. Jurnal Manajemen Pelayanan Kesehatan, 122-129.

Kapucu, N. (2006). Interagency Communication Networks During Emergencies. American Review of Public Administration, 207-225.

Murray, S. F., Davies, S., Phiri, R. K., \& Ahmed, Y. (2001). Tools for Monitoring The Effectiveness of District Maternity Refferal Systems. Health Policy and Planning, 353361

Murray, S., \& Pearson, S. C. (2006). Maternity Referral Systems in Developing Countries: Current Knowledge and Future Research Needs. Social Science \& Medicine, 22052215.

Rowland, T., McLeod, D., \& Froese-Burns, N. (2012). Comparative Study of Maternity System. Wellington: Malatest Press.

Simbolon, D., Chalidyanto, D., \& Ernawati. (2013). Determinan Pelayanan Kesehatan lbu dan Anak di Rumah Sakit Pemerintah Indonesia (Analisis Data Rifaskes 2011). Jurnal Kebijakan Kesehatan Indonesia, 202-2014.

Yonara, S. (2015). Analisis Hambatan Pada Pelaksanaan Rujukan Maternal Kota Surabaya Berdasarkan Teori Interorganizational Coordination. Skripsi. Universitas Airlangga, Surabaya. 